$\xi=-1$

\title{
Is Spiritual Intelligence no Longer Relevant on Business Performance?
}

\author{
Mazni Saad $^{1 *}$, Rosita Husain ${ }^{2}$, Nafiza Mahayuddin ${ }^{3,}$ Aznita Ahmad ${ }^{4}$, Mokana Muthu Kumarasamy $^{5}$ \\ ${ }^{1}$ Kulliyah of Languages and Management, International Islamic University Malaysia, Pagoh Edu Hub KMl, Jalan Panchor, 84600 \\ Pagoh, Muar, Johor, Malaysia. \\ 2,3,4,5 Faculty of Business and Accountancy, Universiti Selangor, Jalan Zirkon A7/A, Seksyen 7, 40000 Shah Alam, Selangor \\ *Corresponding author E-mail:ms_mazni1971@yahoo.com
}

\begin{abstract}
The current study was to examine the mediating role of Spiritual Intelligence (SQ) in engaging employees at the workplace. Particularly, this study aimed to at investigating the SQ in the relationship between practices and business performance among the food handlers. The main objective of this research is to examine the mediating effect of the SQ on the business performance (food, services, and atmosphere). Four main SQ dimensions from the ISIS measurement scale were used as a basis to collect the data. A total of 816 data was collected from the food handlers from different government's off-premises. Analyzed with the Smart PLS, the analysis showed that SQ mediated the relationship between practices and business performance in these three areas. In assessing the structural model estimate, the results of analysis revealed that the direct effect is statistically difference from zero $\left(\beta_{-} c \neq 0\right)$. Thus, rejected the null hypothesis $\beta \_c=0$ with a statistically significance showed that there is a mediating effect on the relationship between practices and business performance. The discussion is made in explanation of these results within the context of other researches and suggestions for further research.
\end{abstract}

Keywords: Business Performance; Employee Engagement; Spiritual Intelligence; Malaysia.

\section{Introduction}

Nowadays, globalization draws challenges for every organization in its efforts to sustain profit and overall business performance. Globalization means more competition, and more competition means more pressure to lower cost and make employees more productive and quality conscious (Dessler, 2017). Maintaining a good workforce does influence the overall organizational performance. This could be obtained through effective employee engagement. Employee engagement is a dimension that refers to an employee's attachment to his or her job, co-workers, and company mostly leads to a positive contribution to the company.

A career success is attained when employees with higher intelligence tend to achieve work target fulfilling the stakeholders' needs. At the same time there is an intense eagerness to learn and develop his or her career path (Shah, Saad, Mohan, and Poniran, 2018). Hence, intangible issues such as Spiritual Intelligence or Spiritual Quotient (SQ) is now in focus as it accelerates not only self-development, but is also a tool for an employee to engage in assuring sustainability of a company.

In recent years, employers in all sectors are becoming more attentive to their employees' wellbeing. This is crucial for the betterment and sustainability of one's organization. Failing to do so, the organization will also face increasing costs in the form of absenteeism, low productivity, health costs, and turnover (Husin, Ghazali, Abdullah, and Hadi, 2017).

With global competition, technological advances, and economic turmoil, human capital is the most important asset and matter to the organization and its overall business performance. Therefore, the main objective of the current research is to examine the mediating effect of SQ on performance.

\section{Literature Review}

\subsection{Spiritual Intelligence}

Scholars have been attempting to study ways of balancing an employees' life. For over a century employees have been using their intelligence quotient (IQ) to analyze, reason, think abstractly, use language, visualize, and comprehend (corresponding to matters of the mind) and in the mid-1990s, Goleman (1995) introduced the importance of the concept of Emotional Intelligence (EQ) which refers more to self-knowledge, self-awareness, social sensitivity, empathy and ability to communicate successfully with others (corresponding to matters of the heart). These are the two elements that have been practiced by employees in work engagement.

In the last decade, a new concept of intelligence called SQ has emerged at the workplace for the purpose of better work, better life and better being since employees are spending most of their productive time at work on a daily basis. Recently, SQ has been associated with leadership effectiveness, best practices and successful business (Saad, Abdullah, Jeinie, \& Husain, 2017; Saad, See, Adil, \& Kassim, 2015).

SQ is more than cognitive and emotional skills. It acknowledges human mortality and the whole approach to humanity. It is about living modestly; bearing in mind that each and every one of us is just a small entity compared to the vastness of the universe. Over- 
all understanding of SQ motivates people to balance their work commitments, time with family and inner growth (Relojo, 2016).

O'Donnell (1997) on the other hand, advocated the integration of SQ with both rational intelligence and EQ. IQ helps us to interact with numbers, formulas, and things, EQ helps us to interact with people and SQ helps us to maintain inner balance. This inner balance is described as the linked causal model of SQ (Tischler et al., 2002 ) as in the following illustration in Figure 1, where " $X$ " refers to other variables.

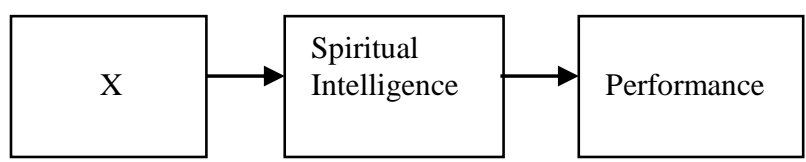

Fig. 1: Spiritual Intelligence Model

Emmons (2000) disputed spirituality as intelligence due to five core abilities, namely: (a) the capacity for transcendence; (b) the ability to enter into heightened spiritual states of consciousness; (c) the ability to invest everyday activities, events, and relationships with a sense of the sacred; (d) the ability to utilize spiritual resources to solve problems in living; and (e) the capacity to engage in virtuous behaviors or to be virtuous (to show forgiveness; to express gratitude; to be humble; to display compassion) (p.10).

Hattangadi (2015) referred to SQ as the spiritual power of a person that increases the ability to be creative, aware and insightful. The individual is able to see his personal vision and the outcome from his effort to achieve the same through an understanding of the larger good of the society, bringing good health and happiness to him and the world at large. Spirituality brings depth to an individual's approach and perspective towards leading a more meaningful life and in turn to positively affect the success of the organization.

\subsection{Spiritual Intelligence and Organizational Perfor- mance}

Literature has witnessed the concept of SQ being a fast emerging catalyst and as the next significant element that is now a growing interest in enhancing many organizations' bottom line. From the extensive research reviews, Singh and Mishra (2016) concluded that spirituality at workplace helps individual in developing leadership skills. SQ helps employees become crucial leaders who respect other people, express care, and concern and develop listening skills in order to give appropriate responses. It also influences social relationships and wisdom that shape job satisfaction and performance while enhancing an atmosphere of joy at the workplace.

In another study of 300 bank employees in Pakistan, Malik and Tariq (2016) discovered that there was a significantly positive relationship between SQ and organizational financial performance in terms of the return of assets (ROA) and Tobin's $Q$ value. The results show that SQ increases organizational performance while age, gender, education and organizational culture act as a moderator in this relationship. The authors concluded that the managers enhance the SQ of employees by increasing the efficiency and effectiveness of their work.

Devi (2016) studied the impact that the religious and the spiritual have on employee engagement. The scholar highlighted that spirituality is able to influence healthy people to perform better in the workplace. The comprehensive EQ framework based components within the organization provide employees with the necessary skills to apply their personal spiritual experience into their work. It helps them to develop strong psychological bonding with the organization which in turn provides positive results for both the employees and the organization.
The studies mentioned have therefore proven that workplace spirituality is a very important culture in every organization as it has a positive impact on the employees at the organizational level. A similar SQ impact on organizational performance is also positively and significantly evident in the service sectors.

In the case of the telecommunication industry, Wahid and Mohd Mustamil (2017) studied the potentials of spiritual well-being through spiritual leadership by employing a spiritual leadership survey called the spiritual leadership balanced scorecard (BSC). The survey had a sample size of 140 employees working in four different telecommunication organizations in Malaysia. Eight quality dimensions that covered most aspects of spiritual wellbeing were measured against Triple Bottom Line (TBL - people, planet, profit were discussed with inner life, hope/faith, altruistic love, calling, membership, productivity, organizational commitment and life satisfaction). The results of the Partial Least Squares Structural Equation Modeling PLS-SEM approach indicates that spiritual leadership has a significant contribution to the TBL of the telecommunication industry in Malaysia, in terms of organizational commitment, productivity, and life satisfaction. The authors also concluded that the relationship between spiritual leadership among the telecommunication leaders in Malaysia was significant enough to positively influence the sense of calling and membership of the followers within the organization. However, the sense of calling only had a minimal contribution to the relationship between organizational performance and TBL.

Using the same BSC approach, Salehzadeh, Khazaei Pool, Kia Lashaki, Dolati, and Balouei Jamkhaneh (2015) investigated the impact of hotel leaders' spirituality on the hotel's performance. 207 middle managers of 60 hotels across eight provinces in Iran were involved in the study. The BSC dimensions of spiritual leadership consisting of calling, membership, and performance were investigated. Using a structural equation modelling (SEM) AMOS, the findings showed that spiritual leadership, calling, and membership have a significantly positive effect on the hotels' performance. The study suggested that spiritual leadership through attention to the members' spiritual needs leads to organizational performance.

Other different dimensions of workplace spirituality have also been studied. Djafri and Noordin (2017) for example empirically examined the Islamic insurance (Takaful) industry of Malaysia. The result of their Pearson correlation coefficient reported not only significant but strong positive correlations between the workplace spirituality dimension and organizational commitment. The authors, therefore, recommend that applying spiritual practices in the workplace might lead to improving and sustaining employees' well-being which will ultimately lead to high-level organizational commitment. In short, SQ does matter as it affects workplace spirituality and spiritual leadership, employee motivation, employee productivity, organizational culture and organizational performance (Mehta \& Joshi, 2010).

\subsection{Spiritual Intelligence as a Mediator}

Recent research has been focusing on the intangible issues of SQ in the hospitality business. In the context of primary health care services, more advanced research on work spirituality was found mediating organizational performance. Albuquerque, Cunha, Martins, and Sa (2014) conducted a study on the influence of three dimensions of workplace spirituality (inner life, meaningful work and sense of community) on perceived and objective organizational performance. For data collection, the researchers distributed questionnaires to 266 health care workers (doctors, nurses and administrative staff) at both health centers and family health units in Portugal. The study highlighted the significant mediation effect of the total spirituality construct on the relationship between the workgroup and perceived and objective organizational performance. Meaningful work and sense of community emerged as 
significant mediating variables in the two types of organizational performance, while inner life did not.

Bodla and Ali (2012) empirically investigated the role of spiritual well-being variables as a mediator between spiritual leadership and individual work outcomes like performance, organizational commitment, and job satisfaction. The research was conducted among bank employees in Pakistan. The two components of a follower's need for spiritual survival/well-being, meaning/calling and membership were measured. With the introduction of calling and membership as a mediator, a partial mediation effect was observed, which points to the existence of a direct relationship between independent and dependent variables. The study concluded that the positive relationship found between spiritual leadership and elements of spiritual survival/well-being had practical implications for effectiveness in banking.

Chen, Yang, and Li (2012) in a similar study adopted Fry et al.'s, (2003) Spiritual Leadership Skill (SLT) to measure a leader's spiritual leadership, vision, hope or faith, and altruistic love and found three types of follower's factors influencing organizational outcomes. They are employee spiritual attribute toward work meaning or calling; employee spiritual attribute toward organization/team - membership; and employee spiritual attribute toward inner self - self-esteem and self-efficacy. Spiritual leadership was found to predict spiritual well-being sub-scales of meaning/calling and membership. Meaning/calling and membership were found to mediate the relationship between spiritual leadership and organizational outcomes. In another related study, Yusof and Mohamad (2014) proposed a conceptual framework in which they hypothesized that the employees' spiritual well-being mediated the influence of leaders' spiritual leadership on employee job satisfaction.

Jurkiewicz and Giacalone (2004) reported the body of research that reviewed and analyzed the positive relationship between the workplace spirituality values framework and the employee that leads to organizational performance. These results are based on work processes, policies, and practices that represent the organizational culture. A later study conducted by Petchsawanga and $\mathrm{Du}-$ chon (2012) also discussed the same issue. According to them, two more studies proved that promoting employees' spiritual selves according to the eastern context will enhance work productivity. The results also show that meditation was found partially mediating the association between workplace spirituality and work performance.

Based on the five studies above, it can be summarized that elements of spirituality have a positive impact on workplace practices. The other mediation effects of SQ were also evident in studies by Habib, Riaz, and Akram (2012) who found that SQ mediates the relationship between EQ and life satisfaction, and Rahimi and Karami (2014) who found that SQ works as a mediator between psychological well-being and life satisfaction. Thus, consistent with the SQ link-causal-model proposed by Tischler et al. (2002), this study aims to examine the potential effects of SQ as a mediator between food-hygiene practices and foodservice performance.

\section{Methodology}

This study wanted to identify the role of SQ as a mediator in the relationship between the practices of food handlers and their business performance in Peninsular Malaysia. Geographically, food handlers are divided according to four main regions, namely Northern, Central, Southern, and Eastern Peninsular Malaysia. The data were obtained through the use of a questionnaire distributed to 816 food handlers. A 6-point Likert scale was used for measurement which was later analyzed by SmartPLS.

\section{Results and Findings}

\subsection{Measurement Model Estimation}

Prior to accessing the structural model, all the elements in measurement model were checked for reliability, convergent validity and discriminant validity. Table 1 shows the measurement model. For all the constructs, all the loading values were more than the cut point value of 0.7 as suggested by Hair et al., (2013). The average variance extracted (AVE) of all the constructs were higher than the suggested value of 0.5 (Bagozzi \& Yi, 1988), while the composite reliability scores (CR) exceeded the recommended value of 0.7 (Hair, Ringle, \& Sarstedt, 2013). Therefore, the convergent validity of this measurement model is achieved.

\begin{tabular}{|c|c|c|c|c|}
\hline Construct & Items & $\begin{array}{l}\text { Outer } \\
\text { Loading }\end{array}$ & $\begin{array}{l}\text { Average } \\
\text { Variance } \\
\text { Extracted } \\
\text { (AVE) }\end{array}$ & $\begin{array}{l}\text { Composite } \\
\text { Reliability }\end{array}$ \\
\hline \multirow{2}{*}{ FHP } & Floor & 0.912 & 0.829 & \multirow{2}{*}{0.907} \\
\hline & Toilet & 0.910 & & \\
\hline \multirow{4}{*}{$\mathrm{SQH}$} & Religious & 0.784 & & \multirow{4}{*}{0.846} \\
\hline & Closeness & 0.718 & 0.580 & \\
\hline & Religiousbook & 0.740 & & \\
\hline & Religiousact & 0.801 & & \\
\hline \multirow{2}{*}{ SQCH } & Pray & 0.840 & 0.689 & \multirow{2}{*}{0.816} \\
\hline & Confidence & 0.820 & & \\
\hline \multirow{2}{*}{ SQSC } & Personality & 0.830 & 0.701 & \multirow{2}{*}{0.824} \\
\hline & Doitright & 0.845 & & \\
\hline \multirow{2}{*}{ SQHC } & Inner & 0.710 & 0.629 & \multirow{2}{*}{0.771} \\
\hline & Insight & 0.869 & & \\
\hline \multirow{4}{*}{ FPFR } & Foodpresentation & 0.845 & & \multirow{4}{*}{0.857} \\
\hline & Foodtemp & 0.716 & 0.600 & \\
\hline & Quality & 0.715 & & \\
\hline & Tasty & 0.815 & & \\
\hline \multirow{3}{*}{ SPFR } & Efficiency & 0.862 & & \multirow{3}{*}{0.832} \\
\hline & Knowprep & 0.732 & 0.624 & \\
\hline & Wellmanners & 0.769 & & \\
\hline \multirow{4}{*}{ APFR } & Decoration & 0.780 & & \multirow{4}{*}{0.860} \\
\hline & Dininghall & 0.753 & 0.605 & \\
\hline & Selfappearance & 0.782 & & \\
\hline & Utilities & 0.796 & & \\
\hline
\end{tabular}

Table 2 shows that all the constructs tested met the discriminant validity criterion. Consistently, the loadings of all the constructs satisfied the criterion. Thus, the discriminant validity is achieved.

\begin{tabular}{|c|c|c|c|c|c|c|c|c|}
\hline & $\begin{array}{l}\text { APF } \\
\text { R }\end{array}$ & $\begin{array}{r}\quad F \\
H P\end{array}$ & $\begin{array}{r}F \\
\text { PRF }\end{array}$ & $\begin{array}{r}\mathrm{S} \\
\text { PFR }\end{array}$ & $\begin{array}{c}\mathrm{S} \\
\mathrm{QCH}\end{array}$ & $\begin{array}{l}\text { SQ } \\
\text { H }\end{array}$ & $\begin{array}{r}\mathrm{SQ} \\
\mathrm{HCC}\end{array}$ & $\begin{array}{c}\mathrm{S} \\
\mathrm{QSC}\end{array}$ \\
\hline $\begin{array}{l}\text { AP } \\
\text { FR }\end{array}$ & $\begin{array}{r}0 . \\
778\end{array}$ & & & & & & & \\
\hline $\mathrm{P}^{\mathrm{FH}}$ & $\begin{array}{r}0 . \\
240\end{array}$ & $\begin{array}{r}0 . \\
911\end{array}$ & & & & & & \\
\hline $\begin{array}{l}\text { FP } \\
\mathrm{RF}\end{array}$ & $\begin{array}{r}0 . \\
568\end{array}$ & $\begin{array}{r}0 . \\
285\end{array}$ & $\begin{array}{r}0 . \\
775\end{array}$ & & & & & \\
\hline $\mathrm{R}^{\mathrm{SPF}}$ & $\begin{array}{r}0 . \\
553\end{array}$ & $\begin{array}{r}0 . \\
254\end{array}$ & $\begin{array}{r}0 . \\
702\end{array}$ & $\begin{array}{r}0 . \\
790\end{array}$ & & & & \\
\hline $\begin{array}{r}\text { SQ } \\
\mathrm{CH}\end{array}$ & $\begin{array}{r}0 . \\
264\end{array}$ & $\begin{array}{r}0 . \\
229\end{array}$ & $\begin{array}{r}0 . \\
354\end{array}$ & $\begin{array}{r}0 . \\
391\end{array}$ & $\begin{array}{r}0 . \\
830\end{array}$ & & & \\
\hline${ }_{\mathrm{H}}^{\text {SQ }}$ & $\begin{array}{r}0 . \\
268\end{array}$ & $\begin{array}{r}0 . \\
173\end{array}$ & $\begin{array}{r}0 . \\
292\end{array}$ & $\begin{array}{r}0 . \\
357\end{array}$ & $\begin{array}{r}0 . \\
582\end{array}$ & $\begin{array}{l}0.76 \\
2\end{array}$ & & \\
\hline $\begin{array}{r}\text { SQ } \\
\mathrm{HCC}\end{array}$ & $\begin{array}{r}0 . \\
258\end{array}$ & $\begin{array}{r}0 . \\
228\end{array}$ & $\begin{array}{r}0 . \\
353\end{array}$ & $\begin{array}{r}0 . \\
362\end{array}$ & $\begin{array}{r}0 . \\
288\end{array}$ & $\begin{array}{l}0.23 \\
2\end{array}$ & $93^{0.7}$ & \\
\hline $\begin{array}{l}\text { SQ } \\
\text { SC }\end{array}$ & $\begin{array}{r}0 . \\
284\end{array}$ & $\begin{array}{r}0 . \\
286\end{array}$ & $\begin{array}{r}0 . \\
413\end{array}$ & $\begin{array}{r}0 . \\
436\end{array}$ & $\begin{array}{r}0 . \\
498\end{array}$ & $\begin{array}{l}0.41 \\
7\end{array}$ & $40^{0.4}$ & $\begin{array}{r}0 . \\
837\end{array}$ \\
\hline
\end{tabular}




\subsection{Structural Model Estimate}

In order to estimate the structural model, a sampling bootstrapping procedure with 1000 resamples was run to generate the t-values. Figure 2 presents the structural model, while Table 3 presents the results of the relationship between the constructs. Evaluating the statistical significance of the mediating effect of SQ involved testing the null hypothesis on the direct effect $\beta \_c\left(H \_0: \beta \_c=0\right.$ against the alternative $\left.H_{-} 1: \beta \_c \neq 0\right)$ ). Table 3 shows the path coefficient for each relationship, also known as the direct effect of each construct. As can be seen, the direct effect is statistically different from zero $\left(\beta \_c \neq 0\right)$. Thus, the null hypothesis $\beta \_c=0$ is rejected, it is statistically significant. Therefore, SQ mediates the relationship between practices and performance.

Table 3: Path Coefficients

\begin{tabular}{|c|c|c|c|c|c|c|c|}
\hline \multirow{2}{*}{\multicolumn{2}{|c|}{ Relationship }} & \multirow{2}{*}{$\begin{array}{l}\text { R- } \\
\text { Squar } \\
\mathrm{e} \\
\end{array}$} & \multirow{2}{*}{$\begin{array}{l}\text { Path } \\
\text { Coeffi- } \\
\text { cient }\end{array}$} & \multirow{2}{*}{$\begin{array}{l}\mathrm{T} \text { Sta- } \\
\text { tistics }\end{array}$} & \multirow{2}{*}{$\begin{array}{l}\text { P } \\
\text { Val- } \\
\text { ues }\end{array}$} & \multicolumn{2}{|c|}{$\begin{array}{l}\text { Confidence } \\
\text { Interval }\end{array}$} \\
\hline & & & & & & Lower & Upper \\
\hline $\begin{array}{l}\text { FHP } \\
\text { SQCH }\end{array}$ & $\rightarrow$ & 0.053 & 0.229 & 7.067 & 0.000 & 0.168 & 0.296 \\
\hline FHP -> SQ & $\mathrm{QH}$ & 0.030 & 0.173 & 5.675 & 0.000 & 0.110 & 0.232 \\
\hline $\begin{array}{l}\text { FHP } \\
\text { SQHCC }\end{array}$ & $\rightarrow$ & 0.052 & 0.228 & 7.508 & 0.000 & 0.172 & 0.289 \\
\hline $\begin{array}{l}\text { FHP } \\
\text { SQSC }\end{array}$ & $\rightarrow$ & 0.082 & 0.286 & 7.780 & 0.000 & 0.220 & 0.355 \\
\hline $\begin{array}{l}\text { SQCH } \\
\text { APFR }\end{array}$ & $\rightarrow$ & 0.131 & 0.082 & 1.837 & 0.067 & -0.012 & 0.167 \\
\hline $\begin{array}{l}\text { SQCH } \\
\text { FPRF }\end{array}$ & $->$ & 0.234 & 0.146 & 3.430 & 0.001 & 0.062 & 0.222 \\
\hline $\begin{array}{l}\text { SQCH } \\
\text { SPFR }\end{array}$ & $\rightarrow$ & 0.272 & 0.147 & 3.555 & 0.000 & 0.073 & 0.228 \\
\hline $\begin{array}{l}\text { SQH } \\
\text { APFR }\end{array}$ & $\rightarrow$ & 0.131 & 0.134 & 3.312 & 0.001 & 0.052 & 0.215 \\
\hline $\begin{array}{l}\text { SQH } \\
\text { FPRF }\end{array}$ & $->$ & 0.234 & 0.068 & 1.819 & 0.070 & -0.004 & 0.142 \\
\hline $\begin{array}{l}\text { SQH } \\
\text { SPFR }\end{array}$ & $\rightarrow$ & 0.272 & 0.135 & 3.642 & 0.000 & 0.064 & 0.207 \\
\hline $\begin{array}{l}\text { SQHCC } \\
\text { APFR }\end{array}$ & $->$ & 0.131 & 0.150 & 3.880 & 0.000 & 0.076 & 0.225 \\
\hline $\begin{array}{l}\text { SQHCC } \\
\text { FPRF }\end{array}$ & $->$ & 0.234 & 0.196 & 5.494 & 0.000 & 0.125 & 0.262 \\
\hline $\begin{array}{l}\text { SQHCC } \\
\text { SPFR }\end{array}$ & $\rightarrow$ & 0.272 & 0.190 & 5.362 & 0.000 & 0.131 & 0.262 \\
\hline $\begin{array}{l}\text { SQSC } \\
\text { APFR }\end{array}$ & $->$ & & 0.121 & 2.669 & 0.008 & 0.034 & 0.207 \\
\hline $\begin{array}{l}\text { SQSC } \\
\text { FPRF }\end{array}$ & $\rightarrow$ & & 0.225 & 5.263 & 0.000 & 0.152 & 0.310 \\
\hline $\begin{array}{l}\text { SQSC } \\
\text { SPFR }\end{array}$ & & & 0.223 & 5.195 & 0.000 & 0.138 & 0.305 \\
\hline
\end{tabular}

Figure 2 shows the relationship between the constructs, there is a positive relationship $(\beta=0.229, \mathrm{p}<0.01)$ between FHP and SQCH explaining $5.3 \%$ variance. Besides, Food-hygiene Practices (FHP) also has a positive relationship with Holistic (SQH) $(\beta=0.173, \mathrm{p}$ 0.01 ) explaining 3\% variance. High Conscious (SQHCC) also has a positive relationship with FHP $(\beta=0.228, \mathrm{p}<0.01)$ explaining $5.2 \%$ variance, as well as a positive relationship with Challenge (SQSC) $(\beta=0.286, \mathrm{p}<0.01)$ explaining $13.1 \%$ variance.

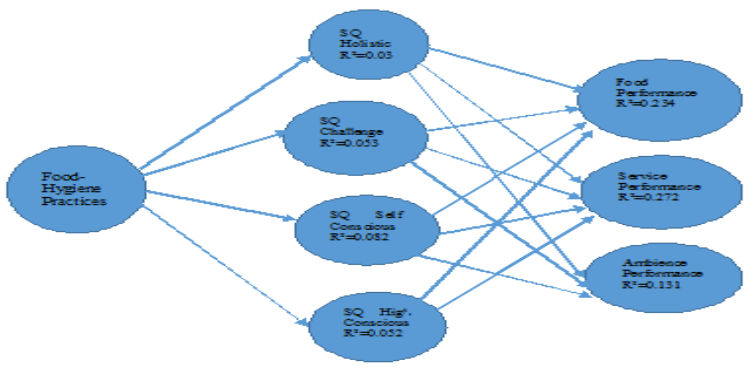

Fig. 2: Spiritual Intelligence as a Mediator
Specifically, this survey elicits information on SQ, food-hygiene practices, and foodservice performance. The results are drawn from the base of empirical investigation in the training camps where food handlers' activities are consistently monitored by the Ministry of Health Malaysia. Four SQ domains (holistic, challenge, self-conscious, and high-conscious) are found to individually mediate the relationship between food-hygiene practices and foodservice performance (food, service, and atmosphere). Specifically, the path coefficient for the mediation path between foodhygiene practices and foodservice performance reveals that there are mediation effects as supported by empirical evidence. Foodhygiene practices have a direct influence on performance with SQ as the mediator. The positive association between these variables shows that empirically spirituality and practicality are interconnected and underlie and support the food handlers' thoughts of self-development and success at work.

This study shows that the indirect effect of food practices on performance is fully mediated by SQ. It is a finding which is in accordance with the research conducted by Albuquerque et al. (2014), Habib, Riaz and Akram (2012) and Pour and Karami (2014). Generally, people with a higher level of SQ have healthier, happier and more productive lives at work (Tischler, Bibierman, \& McKeage, 2002). All employees must, therefore, have a high $\mathrm{SQ}$, as it is a deep feeling of enlightenment that will ultimately guide them into performing their best in the organization. As SQ is considered one of the key factors of success, its overall understanding would motivate people to balance their work commitments, time with family and inner growth Relojo (2016), thus encouraging them to be among the best of food handlers. Implementation of these food handlers' best practices in the business would only encourage the company to willingly implement SQ. This study demonstrates how food practices and SQ are interconnected among the Malaysian food handlers and it is this connection that significantly affects their performance. As implied by Tischler et al. (2002) SQ link-causal-model, the higher the degree of SQ the better the performance. Therefore we conclude that to obtain a higher performance among food handlers, a higher SQ is inevitable.

\section{Conclusion}

We conclude that SQ benefits employees regardless of who they are dealing with and especially the organization they work for. Since the organization is the place where the employees spend most of their time, it is important that SQ be one of the main elements that support business growth. This can be done by creating a more meaningful work environment where employees align personal values with that of the organization's, develop a sense of community belonging, and are empowered with opportunities to grow and develop with the organization.

The findings of the study show important practical implications for organizations to consider SQ's positive impact on employees' work engagement towards the success of the organization. With the large and valid datasets, the positive results reveal that the model proposed in this study could be generalized to the routine practices-and-performances of other foodservice institutions. Producing and presenting quality food, services, and ambiance reflects a sense of obligation in helping others through correct practices while keeping account of one's good deeds for the benefit of one's journey towards the next life. While the current study argues on the effects of the four main domains of SQ in mediating practices in the hospitality business, future studies may consider other SQ criteria listed in ISIS. This study, however, is limited to government-controlled food services. 


\section{Acknowledgement}

The researchers' work is partially supported by Universiti Selangor (UNISEL). Special thanks, particularly the Faculty of Business and Accountancy.

\section{References}

[1] Albuquerque IF, Cunha RC, Martins LSD, \& Sa AB (2014). Primary health care services: workplace spirituality and organizational performance. Journal of Organizational Change Management, 27(1), 59-82.

[2] Bagozzi RP \& Yi Y (1988). On the evaluation of structural equation models. Journal of the Academy of the Marketing Science, 16(1), 74-94

[3] Bodla MA \& Ali H (2012). Workplace spirituality: A spiritual audit of banking executives in Pakistan. African Journal of Business Management, 6(11), 3888-3897.

[4] Chen CY, Yang CY, \& Li CI (2012). Spiritual leadership, follower mediators, and organizational outcomes: Evidence from three industries across two major Chinese societies. Journal of Applied Social Psychology, 42(4), 890-938.

[5] Dessler G (2017). Human Resource Management (Global Edition ed.): Pearson.

[6] Devi S (2016). Impact of spirituality and emotional intelligence on employee engagement. International Journal of Applied Research, 2(4), 321-325.

[7] Djafri F \& Noordin K (2017). The impact of workplace spirituality on organizational commitment: a case study of Takaful agents in Malaysia. Humanomics.

[8] Emmons R (2000). Is spirituality intelligence: problems and prospects. International Journal for the Psychology of Religion, 10(1), 3-26.

[9] Goleman D (1995). Emotional intelligence: why it can matter more than IQ. London: Bloomsbury.

[10] Habib S, Riaz MN \& Akram M (2012). Emotional intelligence as predictor of life satisfaction among nurses: Mediating role of spiritual wellness. Journal of Social Science, 6(1), 73-78.

[11] Hair JF, Ringle CM \& Sarstedt M (2013). A premier on Partial Least Square Structural Equation Modelling (PLS-SEM): SAGA Publication Ltd.

[12] Hattangadi V (2015). Importance of spirituality quotient. Management. http://drvidyahattangadi.com/importance-of-spiritualityquotient/

[13] Husin NA, Ghazali ASM, Abdullah N, \& Hadi MIBA (2017) Work-Life Balance of Malaysian Lecturers. Australian Academy of Business and Economics Review, 4(1), 43-49.

[14] Jurkiewicz C L \& Giacalone RA (2004). A Values Framework for Measuring the Impact of Workplace Spirituality on Organizational Performance. Journal of Business Ethics, 49, 129-142.

[15] Malik MS \& Tariq S (2016). Impact of Spiritual Intelligence on Organizational Performance. Econ Journal, 6(2), 289-297.

[16] Mehta Y \& Joshi S (2010). Impact of Workplace Spirituality on Organization Culture through Improved Employee Productivity. AIMS International Conference on Value-based Management, 1113.

[17] O'Donnell K (1997). Endoquality - as dimensões emotionais e espirituais do ser humano nas organanizões. O'Donnell, K. (1997). Endoquality - as dimensões emotionais e espirituais do ser humano nas organanizões. doi: doi: 10.1080/14766086.2012.688623

[18] Petchsawanga P \& Duchon D (2012). Workplace Spirituality, Meditation, and Work Performance Journal of Management, Spirituality \& Religion, 189-208

[19] Rahimi PM \& Karami E (2014). The Mediating Role of Spiritual Intelligence with Psychological well-being and life satisfaction in Mehriz Elderly Rehab Med., 3(3), 72-81.

[20] Relojo D (2016). Philosophy as a Way of Life: What is Spiritual Quotient? Psychreg Journal of Psychology.

[21] Saad M, Abdullah MFF, Jeinie MH \& Husain R (2017). Reflecting Leadership Effectiveness via Food-hygiene Practices. Asian Journal of Behavioural Studies, 2(8) (2017).

[22] Saad M, See TP, Adil MAM \& Kassim NM (2015). A holistic perspective of spiritual intelligence on leadership effectiveness and food-hygiene practices in government foodservice institutions. Procedia - Social and Behavioral Sciences, 201, 146-155.
[23] Salehzadeh R, Khazaei PJ, Kia LJ, Dolati H \& Balouei JH (2015). Studying the effect of spiritual leadership on organizational performance: an empirical study in the hotel industry. International Journal of Culture, Tourism and Hospitality Research, 9(3), 346-359.

[24] Shah NA, Saad M, Mohan NMM \& Poniran H (2018). Working in private universities: does emotional intelligence matter for job effectiveness? International Journal of Accounting, Finance and Business (IJAFB, 3(10), 87-96.

[25] Singh S \& Mishra DP (2016). A Review on Role of Spirituality at Workplace. The International Journal of Indian Psychology, 3(8).

[26] Tischler L, Bibierman J \& McKeage R (2002). Linking emotional intelligence, spirituality and workplace performance: Definitions models and ideas for research. Journal of Managerial Psychology, 17(3), 203-218.

[27] Yusof JM, \& Mohamad M (2014). The Influence of Spiritual Leadership on Spiritual Well-Being and Job Satisfaction: A Conceptual Framework. International Review of Management and Business Research, 3(4), 1948 